\title{
Impact of Preparation of Titanium Alloys on Their Abrasive Water Jet Machining
}

\author{
Adam Štefek * and Martin Tyč \\ Department of Physics, Faculty of Electrical Engineering and Computer Science, \\ VSB-Technical University of Ostrava, 17. listopadu 2172/15, 70800 Ostrava, Poruba, Czech Republic; \\ martin.tyc.st@vsb.cz \\ * Correspondence: adam.stefek.st@vsb.cz; Tel.: +420-59-732-3128
}

check for updates

Citation: ̌tefek, A.; Tyč, M. Impact of Preparation of Titanium Alloys on Their Abrasive Water Jet Machining. Materials 2021, 14, 7768. https:// doi.org/10.3390/ma14247768

Academic Editors: S. Joseph Poon and Libor M. Hlavac

Received: 15 November 2021 Accepted: 13 December 2021 Published: 16 December 2021

Publisher's Note: MDPI stays neutral with regard to jurisdictional claims in published maps and institutional affiliations.

Copyright: (c) 2021 by the authors. Licensee MDPI, Basel, Switzerland. This article is an open access article distributed under the terms and conditions of the Creative Commons Attribution (CC BY) license (https:// creativecommons.org/licenses/by/ $4.0 /)$.
Abstract: Several titanium alloys, i.e., grade $2 \mathrm{Ti}$, Ti6Al4V and NiTi alloy, prepared by selected deformation procedures were subjected to abrasive water jet (AWJ) cutting and subsequently analysed. The study describes samples' preparations and respective material structures. The impact of deformation processing of the selected alloys on the declination angle during cutting, and the results of measurements of surface wall quality performed for the selected samples at the Department of Physics of Faculty of Electrical Engineering and Computer Science at VŠB-Technical University of Ostrava, are presented and discussed, as are also the influences of structural features of the processed titanium alloys on surface qualities of the investigated samples. The results showed that the highest resistance to AWJ machining exhibited the Ti6Al4V alloy prepared by forward extrusion. Its declination angle (recalculated to the thickness $10 \mathrm{~mm}$ to compare all the studied samples) was $12.33^{\circ}$ at the traverse speed of $100 \mathrm{~mm} / \mathrm{min}$, pumping pressure of $380 \mathrm{MPa}$, and abrasive mass flow rate of $250 \mathrm{~g} / \mathrm{min}$.

Keywords: abrasive water jet; cutting; declination angle; traverse speed; sample preparation

\section{Introduction}

Titanium is one of the high-tech materials featuring high corrosion resistance, low density and elasticity modulus, low thermal conductivity and high strength [1]. Ti and its alloys are widespread throughout many industrial and commercial branches, as well as in medicine [2-4]. For example, due to the high corrosion resistance and low thermal conductivity, $\mathrm{Ti}$ has promising applicability in the aerospace industry as it can be used to protect plastic composite cores from heat and moisture [5]. The same favourable properties also predetermine the usage of this material in dentistry and orthopaedics [6]. Nevertheless, the advantageous behaviour of products made of Ti alloys can be supported by optimised processing of the alloys via plastic deformation, which can favourably affect the structures and consequently the properties of Ti -based materials [7-9].

Many experiments involving severely deformed and thermomechanically processed Ti-based alloys were performed in the past. For example, the severe plastic deformation (SPD) method of equal channel angular pressing (ECAP) was used to alter the properties of CP (commercial purity) Ti [10-12], as well as to manufacture ultra-fine grained samples from Ti6Al4V [13,14], NiTi alloys [15,16] or various biocompatible Ti-based alloys [17,18]. The influence of the aging of titanium alloys at a certain temperature was well described by Gupta et al. [19,20]. Samples of titanium alloy Ti-5Al-3Mo-1.5V were forged at certain temperature and deformed and subsequently heat treated in three different ways. The effect of aging of these samples was then examined. With increasing aging time $(8 \mathrm{~h})$ and higher aging temperature $\left(540^{\circ} \mathrm{C}\right)$ there was an increase in strength, hardness, but at the same time a decrease in the maximum elongation of the sample. This was caused by the formation of a secondary alpha phase that acted as a precipitate [19]. 
Due to the fact that the final products made from the deformation processed materials have to be finished by machining, researchers have also devoted their efforts to finding optimised machining processes and determining the ideal machining parameters for Tibased materials.

The growing need to machine Ti-based alloys, widely used in almost all branches of industry, to produce components with high quality and precision, leads to the research and development of alternative machining tools. Some kinds of modern materials, including Ti-based alloys, are hard to be machined by conventional methods, due to overheating and quick blunting of tools, its clogging or destruction, which can be caused by high ductility of the machined material, its low thermal conductivity, etc. Therefore, unconventional machining methods can be suitable alternatives, although, given by their flexibility (nonstiffness), their precision can be lower than that of the classical tools.

Despite the fact that many new machining methods, such as laser beams or electroerosive processes, have been studied, one of the most used and investigated machining tools is the abrasive water jet (AWJ). The research of this tool has been carried on for years and is still ongoing [21,22]. AWJ is a universal tool that has been used for more than 40 years to machine various materials. It has been tested namely for cutting [23], milling [24-27] and peening [28,29]. However, cutting is the most developed application of AWJ. The main purpose of the majority of published studies was to predict the average depth of cut of the jet, and the final quality of the surface subjected to milling. A thorough description of AWJ machining was performed by Hashish [30,31], who adopted previous models of removing the material in deformation mode (published by Bitter [32,33]), and removing the material in cutting mode (studied by Sheldon and Finnie [34,35]). Later on, some further models based either on a large amount of experimental work [36,37], or on theoretical descriptions of the processes [38,39], were presented. Several statistical models were also presented [40-43], but their validity on materials studied under experimental conditions is limited, as demonstrated e.g., in [44].

Models of the interactions of AWJ with specimens' surfaces are of great importance. Some of them consider material parameters, such as Young modulus of elasticity, grain size, material strength and density, while others are based on the previous determination of experimental values. However, most of the models can be used solely for brittle materials [45-47], or ductile ones [48-50]. The models can only rarely be applied for both the material groups. These are namely the analytical models, e.g., model derived from physical analysis of the process [39]. Nevertheless, the application of such models still requires initial experimental testing to be performed on the investigated material to determine its response to AWJ. Therefore, the analytical models are not commercially used. The description of jet trajectory and its curvature is an essential part of all the used models. Hlavác [38] defined the curvature of the trajectory within the material through the declination angle. Figure 1 shows a comparison of the declination angle measurement of the two samples with different traverse speed set up. It is clearly visible that with increasing depth of cut, the quality of the wall surface deteriorates. Moreover, the curvature (declination angle) of the jet increases and therefore it is possible to relate the quality of the wall with the declination angle. This phenomenon is a consequence of the decreasing energy of the jet in a material. The declination angle can also be used to determine the parameter of machinability [39]. Based on these facts, information about the machinability of the respective material can be acquired just via performing a single experimental cut unlike complicated calculations via completely theoretical model. Moreover, some of the constants in the theoretical model are hard to determine and it is more time consuming than the above-mentioned semi-experimental method.

The conclusions presented in the study [39] were considered during determining the cutting parameters in this presented investigation.

All the referenced works point to the importance of further studying AWJ machining of titanium and its alloys, namely Ti6Al4V. The presented study is aimed at determination of machinability of selected Ti-based materials, it primarily characterises the effects of material 
structures imparted by the intensive plastic deformation-based preparation processes on the AWJ machining - cutting process. Evaluation of the machinability was performed based on the declination angle.

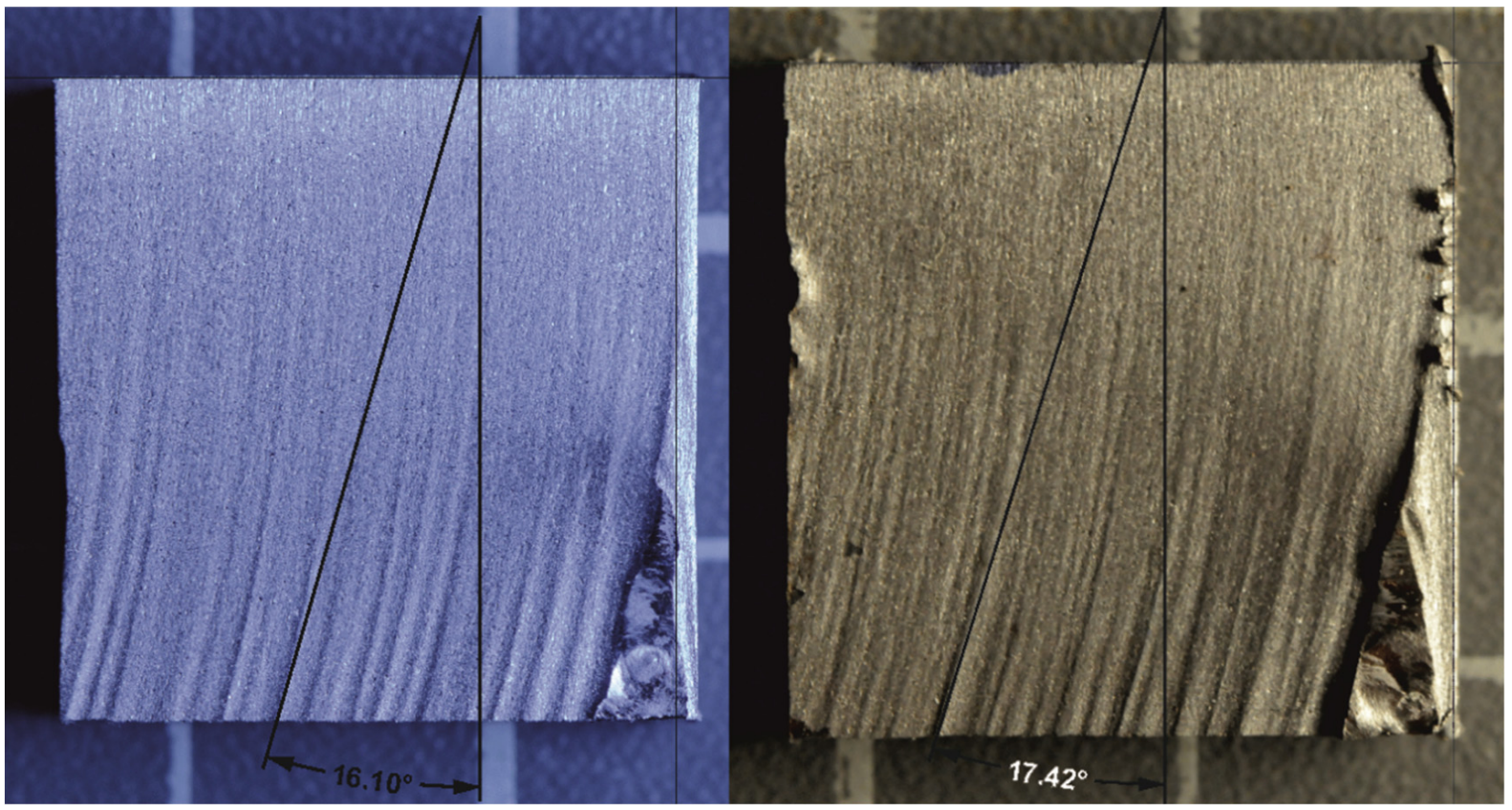

(a)

(b)

Figure 1. The declination angle measurement for titanium samples with traverse speed of $60 \mathrm{~mm} / \mathrm{min}(\mathbf{a})$ and $75 \mathrm{~mm} / \mathrm{min}(\mathbf{b})$.

\section{Experimental Setup}

The experiments were performed in the Laboratory of Liquid Jet at the Faculty of Electrical Engineering and Computer Science at VŠB-Technical University of Ostrava. An AWJ x-y cutting table with manually driven z-axis PTV WJ1020-1Z-EKO (PTV s.r.o., Hostivice, Czech Republic) was used (Figure 2).

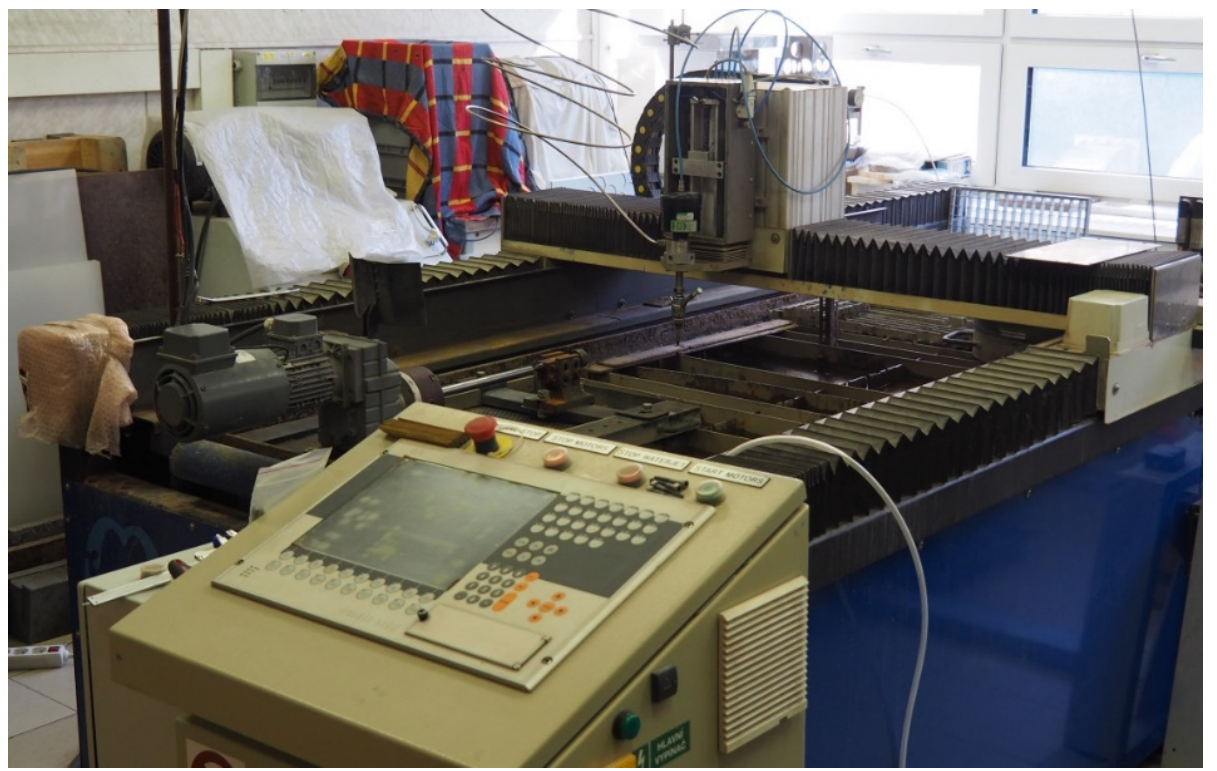

Figure 2. Abrasive waterjet laboratory with PTV WJ1020-1Z-EKO device. 
Selected AWJ parameters were constant during the experiments (summarised in Table 1).

Table 1. Setup of basic experimental variables of AWJ (fixed variables).

\begin{tabular}{cc}
\hline Pumping pressure $(\mathrm{MPa})$ & 380 \\
Water orifice diameter $(\mathrm{mm})$ & 0.25 \\
Focusing tube diameter $(\mathrm{mm})$ & 0.76 \\
Focusing tube length $(\mathrm{mm})$ & 76 \\
Stand-off distance $(\mathrm{mm})$ & 2 \\
Abrasive mass flow rate $(\mathrm{g} / \mathrm{min})$ & 250 \\
Abrasive (Australian garnet) grain size & $80 \mathrm{MESH}$ \\
\hline
\end{tabular}

For the AWJ experiments, samples from six individual Ti-based materials manufactured under various thermomechanical conditions affecting the materials' structures were prepared. Those were subsequently cut via the water jet and the respective declination angles on the kerf walls were measured. Summary of the samples taken from the selected materials manufactured at the Faculty of Materials Science and Technology, VŠB-Technical University of Ostrava, via vacuum induction melting (VIM), and subsequent processing via equal channel angular pressing (ECAP), forward extrusion, or rotary swaging, is given in Table 2. Sample number 5a was not cut with AWJ. However, the microstructure analysis of this sample was performed for comparison with sample $5 b$, which was rotary swaged.

Table 2. Characterization of individual samples and their preparation methods.

\begin{tabular}{ccc}
\hline Sample & Material & Manufacturing \\
\hline Sample 1a & TiCP2 & room-temperature two pass ECAP \\
Sample 1b & TiCP2 & room-temperature two pass ECAP, 10 years of aging \\
Sample 2 & Ti6A14V & hot forward extrusion $\left(900{ }^{\circ} \mathrm{C}\right)$ \\
Sample 3 & Ti6Al4V & hot forging $\left(900^{\circ} \mathrm{C}\right.$, deformation ratio $\left.60 \%\right), 4$ years of aging \\
Sample 4 & Ti6A14V & three-step cold stamping (deformation ratio $45 \%), 4$ years of aging \\
Sample 5a & $50 \mathrm{Ni}-50 \mathrm{Ti}$ & as-cast by VIM \\
Sample 5b & $50 \mathrm{Ni}-50 \mathrm{Ti}$ & rotary swaged after VIM (swaging degree 0.9) \\
Sample 6 & TiCP2 & as-cast, aging unknown \\
\hline
\end{tabular}

All of the measured samples are shown in Figure 3.

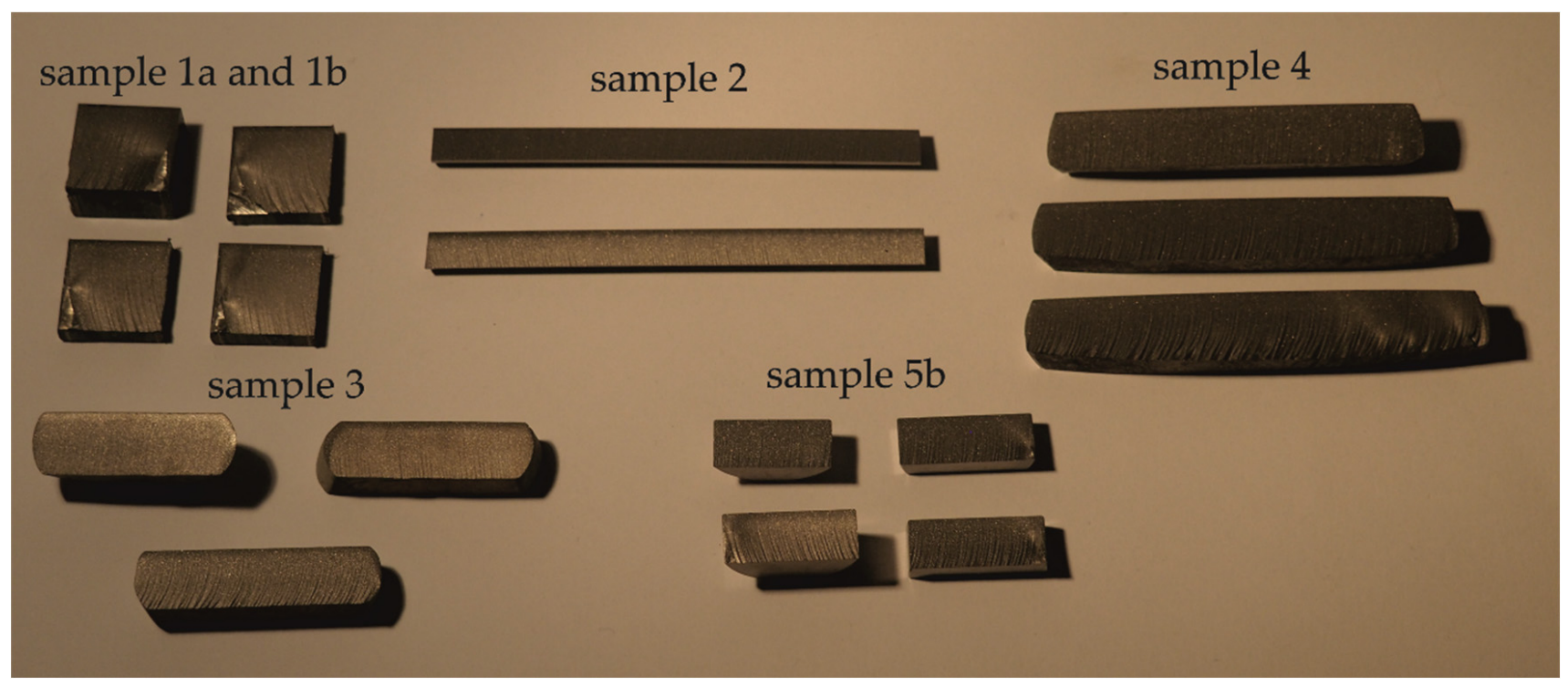

Figure 3. Investigated samples with different dimensions. 
Microstructural observations of the prepared samples were carried out using Olympus DSX1000 digital optical microscope (Olympus Corp., Tokyo, Japan), scanning electron microscope (SEM) Lyra 3 XMU (Tescan, Brno, Czech Republic). Detailed examination of the sample prepared via ECAP was performed using the transmission electron microscope (TEM) JEM-2100 (JEOL, Tokyo, Japan) operating at $200 \mathrm{kV}$. The preparation of samples taken from the selected material states was carried out via combining manual grinding on $\mathrm{SiC}$ papers and polishing using colloidal silica. The foil for TEM was finished by electrolytical etching.

The thicknesses of the samples and the respective traverse speeds used for cutting are listed in Table 3. The samples were left in their "natural" thicknesses produced during the preparation processes to prevent inducing possible changes during machining performed to prepare samples with identical thicknesses. Samples have been collected over the years as a by-product of previous research. Some of them were even stored for several years. The structural changes, which took place at room temperature throughout the years are marked as natural aging. As the samples were not primarily intended to measure and evaluate the declination angle, their thicknesses varied and therefore different traverse speeds were used to achieve a similar surface quality. The chosen traverse speed depended also on the material structure and composition. The traverse speed sets for each of the samples were determined according to the experimental cut and material thickness based on the model presented in [39]. The speed sets were selected so that, if possible, the declination angles varied between $10^{\circ}$ and $30^{\circ}$. The selected range of speeds and relevant angles corresponded to the most common industrial requirements on quality (also considering the economics of the process). After the AWJ cuts were performed, the kerf walls were photographed and the declination angles were measured on them ten times in the CorelDRAW ${ }^{\circledR}$ Home \& Student 2018 software [51] according to the methodology presented first in ref. [38] and used in the Laboratory of Liquid Jet at Faculty of Electrical Engineering and Computer Science at VSB-Technical University of Ostrava.

Table 3. Summary of traverse speed sets for examined material samples and samples' thicknesses.

\begin{tabular}{ccc}
\hline Sample & Material Thickness $(\mathbf{m m})$ & Traverse Speed Sets $(\mathbf{m m} / \mathbf{m i n})$ \\
\hline Sample 1a & 20 & $30,40,60$ \\
Sample 1b & 20 & $50,75,100,125$ \\
Sample 2 & 8 & $100,150,200$ \\
Sample 3 & 12 & $100,150,200$ \\
Sample 4 & $12.5-13.5$ & $100,150,200$ \\
Sample 5b & 10 & $100,150,200$ \\
Sample 6 & 25 & $30,60,90$ \\
\hline
\end{tabular}

\section{Results}

\subsection{Microstructural Observations}

Sample 1a was prepared from a TiCP2 10-10x120 mm billet extruded via double-pass ECAP through a die with $90^{\circ}$ angle; the TEM image of the (sub)structure of this sample is presented in Figure 4a. It is visible that the structure of the sample contained fine grains featuring a high density of dislocations accumulating in the dislocation cells, as well as forming sub grains. These structure phenomena contributed to the increased hardness observed just after the preparation.

The material has also been subjected to 10 years of natural aging; the substructure of Sample 1b, characterised with a large portion of dislocations-free recrystallised grains, is depicted in Figure $4 \mathrm{~b}$. Both the samples were taken from transversal cuts through the processed billet.

Sample 2 was prepared from the Ti6Al4V alloy manufactured by hot forward extrusion $\left(900{ }^{\circ} \mathrm{C}\right)$. The extruded rod with a diameter of $8 \mathrm{~mm}$ was cut along the extrusion axis to prepare the sample. The image of the structure of sample 2, taken from the axial longitudinal cut, acquired via SEM, is presented in Figure 5a. The figure shows significantly 
deformed alpha and beta phase grains elongated in the direction of the dominant plastic flow, i.e., in the extrusion direction.

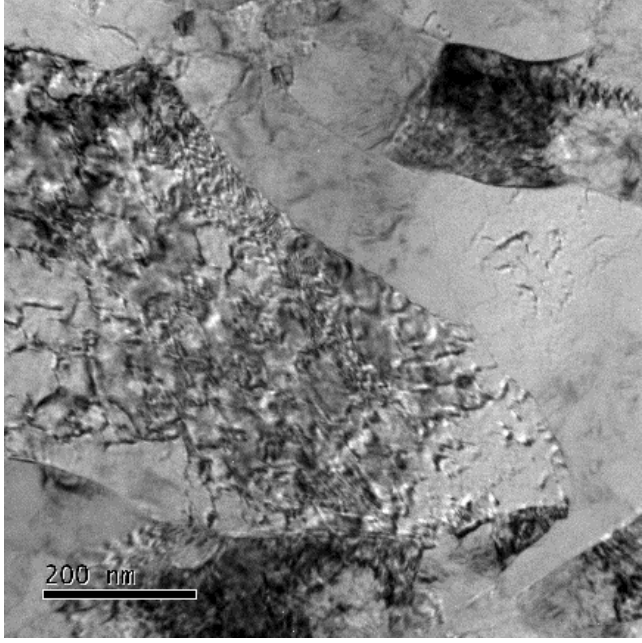

(a)

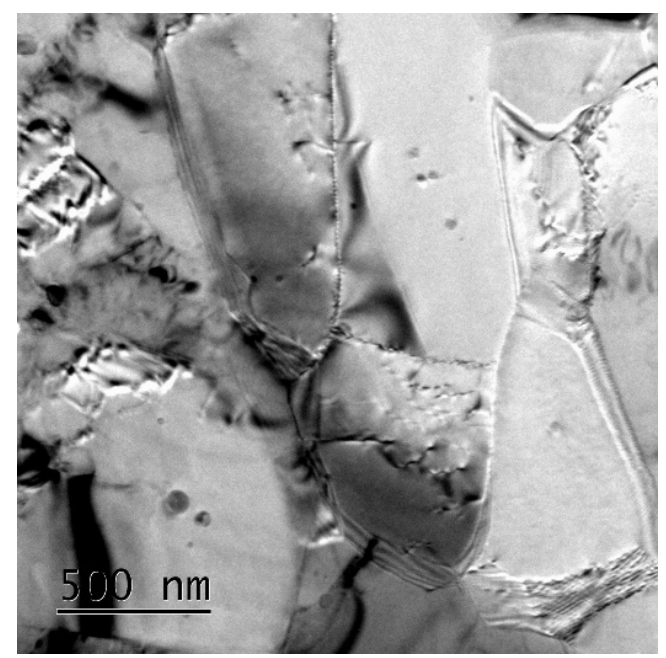

(b)

Figure 4. Substructures of: Sample 1a (a); Sample 1b (b).

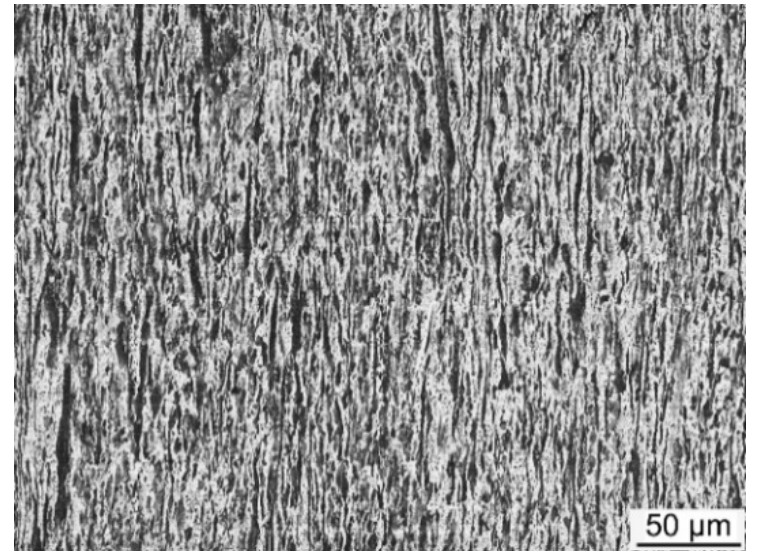

(a)

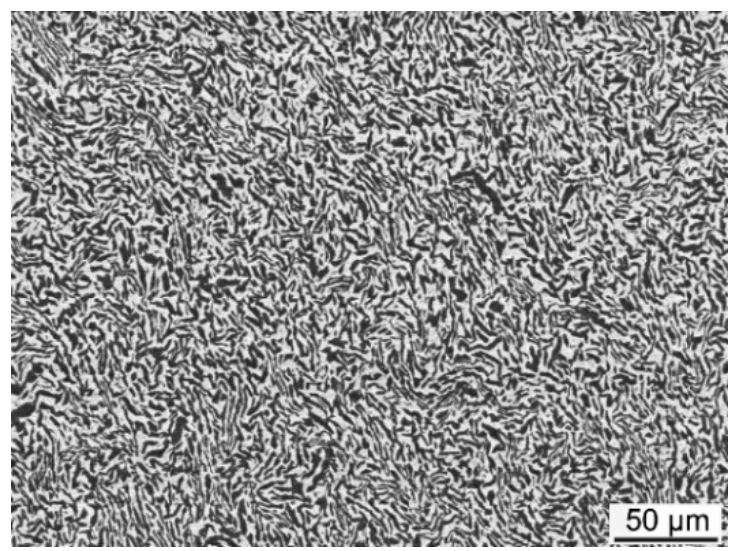

(b)

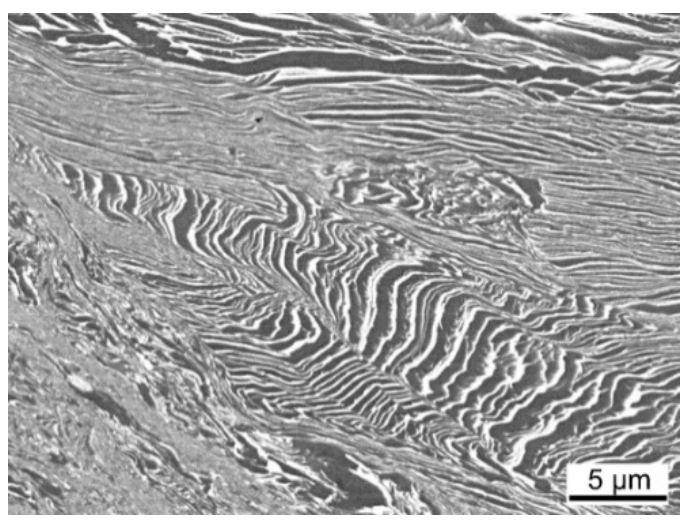

(c)

Figure 5. Structures of Ti6Al4V samples: sample 2-axial cut from rod subjected to hot forward extrusion (a); sample 3-transversal cut from rod subjected to hot forging (b); sample 4-transversal cut from rod subjected to three-step cold stamping (c). 
Another Ti6Al4V sample, denoted in this work as sample 3, was hot forged at $900{ }^{\circ} \mathrm{C}$, from a rod with the original diameter of $10 \mathrm{~mm}$, with the deformation ratio of $60 \%$ (in the direction parallel to the forged rod axis). Before the examination, the material was naturally aged for 4 years. The microstructure of this sample, depicted in Figure 5b, was analysed via SEM in the direction perpendicular to the original forging axis. In other words, sample 2 was examined in the longitudinal direction of the forged rod to demonstrate the effects of forging on elongation of the grains, whereas sample 3 was examined in the transversal direction to show the effects of the deformation performed in the perpendicular direction. Figure $5 \mathrm{~b}$ clearly depicts the deformed alpha and beta phase grains.

The last sample prepared from the Ti6Al4V alloy was sample 4, which was deformed by three consequential deformation (stamping) steps at room temperature, i.e., under cold conditions, with the total deformation ratio of $45 \%$. Before examination, the material was again naturally aged for 4 years, similar to sample 3 . The deformation was performed on the originally extruded rod in the direction parallel to the extrusion axis. The structure acquired via SEM from the transversal cut of the stamped extruded rod is depicted in Figure $5 c$. The image again clearly depicts deformed alpha and beta grains. The grains are evidently heavily deformed and even shear bands start to develop, since the restoration processes during the room-temperature deformation were aggravated.

Further, samples from a NiTi alloy, the chemical composition of which was (in wt.\%) $50 \% \mathrm{Ni}$ and $50 \% \mathrm{Ti}$, were prepared. This alloy was, in the first step, prepared by VIM. From the as-cast rod, a sample in the transversal direction was prepared (sample 5a, the image of the structure of which acquired via optical microscopy is depicted in Figure 6a). Subsequently, the cast rod was processed via rotary swaging with a total deformation ratio of $0.9[52,53]$. The structure image of sample $5 b$, taken from the swaged rod, acquired via optical microscopy is shown in Figure $6 \mathrm{~b}$.

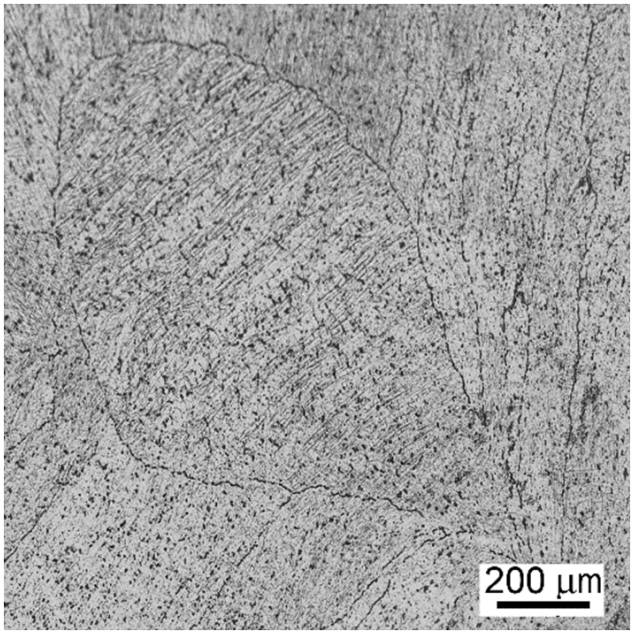

(a)

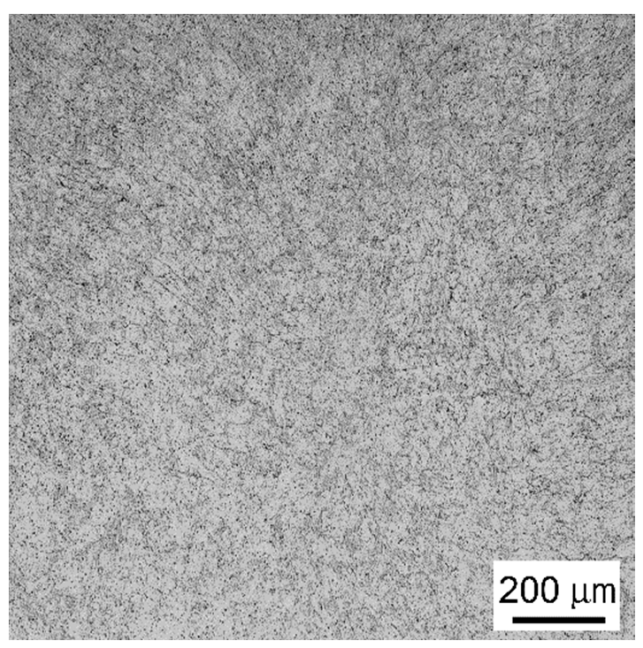

(b)

Figure 6. Structures of NiTi samples: sample 5a-as-cast, prepared by VIM (a); sample 5b-as-cast and rotary swaged $(\mathbf{b})$.

Last but not least, an additional sample (sample 6) from an as-cast CPTi2 plate without any mechanical or thermomechanical treatment was prepared. The structure of this sample was not prepared, since all the cut pieces were handed over to further processing and evaluation of kerf walls immediately after cutting. The sample was selected since the age of this sample was unknown, which enables final verification of the used model on the estimation of the probable age of this sample. 


\subsection{Declination Angles}

Mean values of the declination angles were calculated for all the cuts of all the prepared samples. The results for all the samples, their respective thicknesses and traverse speeds are summarised in Table 4 . Relative uncertainty for all the measurements was $1-5 \%$.

Table 4. Average declination angles measured for examined samples.

\begin{tabular}{cccc}
\hline Sample & Thickness $(\mathbf{m m})$ & $\begin{array}{c}\text { Traverse Speed } \\
(\mathbf{m m} / \mathbf{m i n})\end{array}$ & $\begin{array}{c}\text { Average Declination } \\
\text { Angle } \mathbf{(}^{\circ}\end{array}$ \\
\hline Sample 1a & 20 & 30 & 10.26 \\
& & 40 & 12.73 \\
& 20 & 60 & 19.18 \\
\hline Sample 1b & & 50 & 12.46 \\
& & 75 & 17.36 \\
& & 100 & 21.80 \\
& & 125 & 26.31 \\
\hline Sample 2 & & 100 & 10.43 \\
& & 150 & 12.31 \\
& 12 & 200 & 15.66 \\
\hline Sample 3 & & 100 & 12.25 \\
& & 150 & 17.30 \\
& 12.5 & 200 & 27.00 \\
\hline Sample 4 & 13.2 & 100 & 13.80 \\
& 13.5 & 150 & 21.52 \\
& 10 & 200 & 32.60 \\
\hline Sample 5b & & 100 & 11.36 \\
& & 150 & 15.36 \\
& & 200 & 21.66 \\
\hline & & 30 & 10.72 \\
& & 60 & 24.03 \\
& & 90 & 42.52 \\
\hline
\end{tabular}

Since the conditions of these measurements are different, the declination angle needs to be recalculated through the theoretical model to the same conditions. Therefore, this investigation builds on previous research made by Hlaváč et al. His research was focused on verification of the theoretical model describing final declination angle on two different Titanium samples [23].

\section{Discussion}

To perform a thorough study, the AWJ cuts were performed for a variety of samples with slightly different dimensions, and under numerous traverse speeds. Therefore, due to the fact that the initial conditions were different for the individual cuts, the theoretical model by Hlaváč presented in [38,39], which was used in this study, was applied after the declination angles were recalculated for the ideal thickness of $10 \mathrm{~mm}$ for all the samples, and the traverse speeds were unified to $100 \mathrm{~mm} / \mathrm{min}$. These recalculated values for the respective experimental results are summarised in Table 5 .

As regards the CPTi2 material, the comparison of samples 1a and $1 \mathrm{~b}$, prepared from a CPTi2 billet via room-temperature ECAP, and room-temperature ECAP followed by 10 years of natural aging, respectively, provides the basis to acquire the "rheology factor" for this material. The average calculated "degradation factor" for the CPTi2 billet, determined from the difference between the average declination angle values of $11.55^{\circ}$ for the asprocessed billet and $8.03^{\circ}$ for the billet after 10 years of aging, is $0.35^{\circ}$ per year. 
Table 5. Declination angles recalculated from measured average declination angles for individual samples to values corresponding to the thickness of $10 \mathrm{~mm}$ and traverse speed of $100 \mathrm{~mm} / \mathrm{min}$, also including correction for aging and average angle with aging.

\begin{tabular}{|c|c|c|c|c|}
\hline & MADA * $\left(^{\circ}\right)$ & $\operatorname{RADA}^{* *}\left({ }^{\circ}\right)$ & $\begin{array}{c}\text { RADA ** with } \\
\text { Aging }\left({ }^{\circ}\right)\end{array}$ & $\begin{array}{c}\text { Average RADA }{ }^{* *} \text { with } \\
\text { Aging }\left({ }^{\circ}\right)\end{array}$ \\
\hline Sample 1a & 10.26 & 12.09 & 12.09 & \multirow{3}{*}{11.55} \\
\hline \multirow{2}{*}{0 years } & 12.73 & 11.26 & 11.26 & \\
\hline & 19.18 & 11.30 & 11.30 & \\
\hline Sample 1b & 12.46 & 8.81 & 12.32 & \multirow{4}{*}{8.03} \\
\hline \multirow{3}{*}{10 years } & 17.36 & 8.18 & 11.70 & \\
\hline & 21.80 & 7.71 & 11.22 & \\
\hline & 26.31 & 7.44 & 10.96 & \\
\hline Sample 2 & 10.43 & 14.58 & 14.58 & \multirow{3}{*}{12.33} \\
\hline \multirow[t]{2}{*}{0 years } & 12.31 & 11.46 & 11.46 & \\
\hline & 15.66 & 10.94 & 10.94 & \\
\hline Sample 3 & 12.25 & 9.32 & 10.72 & \multirow{3}{*}{10.85} \\
\hline \multirow[t]{2}{*}{4 years } & 17.30 & 8.77 & 10.17 & \\
\hline & 27.00 & 10.27 & 11.67 & \\
\hline Sample 4 & 13.80 & 9.87 & 11.27 & \multirow{3}{*}{11.31} \\
\hline \multirow[t]{2}{*}{4 years } & 21.52 & 9.46 & 10.86 & \\
\hline & 32.60 & 10.39 & 11.79 & \\
\hline Sample 5b & 11.36 & 11.36 & 11.36 & \multirow{3}{*}{10.81} \\
\hline \multirow[t]{2}{*}{0 years } & 15.36 & 10.24 & 10.24 & \\
\hline & 21.66 & 10.83 & 10.83 & \\
\hline Sample 6 & 10.72 & 9.04 & 10.09 & \multirow{3}{*}{11.42} \\
\hline \multirow[t]{2}{*}{3 years } & 24.03 & 10.13 & 11.18 & \\
\hline & 42.52 & 11.95 & 13.00 & \\
\hline Sample 6 & 10.72 & 9.04 & 10.44 & \multirow{3}{*}{11.77} \\
\hline \multirow[t]{2}{*}{4 years } & 24.03 & 10.13 & 11.53 & \\
\hline & 42.52 & 11.95 & 13.35 & \\
\hline
\end{tabular}

*MADA—-measured average declination angle; ** RADA—recalculated average declination angle.

This calculated "degradation factor" was further applied also during the evaluation of other samples subjected to natural aging before processing, i.e., the Ti6Al4V samples, sample 3 and sample 4 . The declination angles, calculated using this factor, are also depicted in Table 5. For the last sample (sample 6), the age of which is not exactly known (according to internal records estimated to be 3 to 4 years), it is also possible to determine the probable aging time after the preparation of the sample. Both the values were calculated, i.e., for the estimated aging of 3 years and for the estimated aging of 4 years. The respective values were added into Table 5.

Comparing the declination angles recalculated for the identical material thicknesses and the identical traverse speeds, it is evident that Sample 2 made of Ti6Al4V has the lowest machinability (the highest declination angle). The lowest declination angle was acquired during cutting of Sample $1 \mathrm{~b}$ (TiCP2), which was extruded through the ECAP matrix 10 years ago and is now evaluated. Nevertheless, Sample 1a was cut for the first time shortly after its processing. The average declination angle determined from the photo of the cut made on the originally processed material is substantially higher. Because the declination angle is closely related to the material properties of the sample, it is obvious that these properties, imparted by the original mechanical and/or thermal treatment, change in time. Therefore, it is necessary to take the time rheology into account when optimising the material treatment.

When the "rheology factor", determined for Sample 1, is used also for other materials refined by mechanical and thermal processes, and subsequently subjected to natural aging (sample 3 and sample 4), the resulting average declination angle, the measure of the 
material resistance to the AWJ machining, can easily be used for comparison of materials in their original states. It is evident that the lowest average declination angle (the most favourable machinability) has the TiNi alloy (sample 5b). The highest average declination angle (the least favourable machinability) has the Ti6Al4V alloy prepared by forward hot extrusion (sample 2). It is evident that the machinability of the TiCP2 material is similar to that observed for the as-processed sample after 2 ECAP passes (sample 1a) and in the expected as-processed of the as-cast sample (sample 6). The Ti6Al4V alloy has lower average declination angles (better machinability) compared to the as-processed TiCP2, nevertheless the average declination angle is lower for the hot forged Ti6Al4V sample (sample 3), while for the three-step cold stamping Ti6Al4V sample, it is close to the as-processed TiCP2 samples.

\section{Conclusions}

The experiments performed on selected TiCP 2 and Ti-based alloys samples show that their resistance to AWJ cutting depends on the type of material, its preparation, and time of ageing. The hot forward extruded Ti6Al4V is the most resistant from the studied Ti6Al4V samples, while the hot forged Ti6Al4V seems to be the less resistant among them. However, the relative difference between these two materials is only $12.8 \%$. The TiNi alloy is the least resistant of all the studied samples, as it was expected due to the Ni presence. The TiCP2 and the cold stamped Ti6Al4V have similar resistances because the differences are not exceeding the typical uncertainty of the selected experimental procedure and data processing $(5 \%)$. The most important result seems to be the influence of material aging documented on TiCP2 sample processed by the ECAP technology-extrusion through a rectangular channel. The sample subjected to 10 years of natural aging was found to have $30 \%$ reduction in the AWJ machining resistance. Therefore, special attention must be paid to the rheology of materials treated by mechanical processes (extrusion, forging, rolling).

Author Contributions: Conceptualisation, A.క̌.; methodology, M.T.; investigation, A.Š. and M.T.; resources, M.T.; data curation, A.Š. and M.T.; writing—original draft preparation, A.Š.; writingreview and editing, M.T.; visualisation, A.Š.; funding acquisition, A.Š. and M.T. All authors have read and agreed to the published version of the manuscript.

Funding: This research was funded by the Ministry of Education, Youth and Sports of the Czech Republic, project number SP2021/64.

Institutional Review Board Statement: Not applicable.

Informed Consent Statement: Not applicable.

Data Availability Statement: No public data were reported.

Acknowledgments: The authors would like to acknowledge the help of Radim Kocich and Lenka Kunčická and the infrastructure of the Institute of Physics of Materials, Czech Academy of Sciences, Brno, Czech Republic, during preparation of material and structural evaluations.

Conflicts of Interest: The authors declare no conflict of interest.

\section{References}

1. Russell, K.L. Lee. Structure-Property Relations in Nonferrous Metals, 1st ed.; John Wiley \& Sons, Inc.: Hoboken, NJ, USA, 2005.

2. Lutjering, G.; Williams, J.C. Titanium; Springer: Berlin, Germany, 2003.

3. Greger, M.; Kocich, R.; Kander, L.; Jonsta, P. Nanostructured titanium for dental applications. In Proceedings of the Metal 2010 19th International Conference on Metallurgy and Materials, Roznov pod Radhostem, Czech Republic, 18-20 May 2010; Tanger Ltd: Ostrava, Czech Republic, 2010; pp. 182-186.

4. Zach, L.; Kunčická, L.; Růžička, P.; Kocich, R. Design analysis and verification of a knee joint oncological prosthesis finite element model. Comput. Biol. Med. 2014, 54, 53-60. [CrossRef]

5. Rishi, P.; Ramulu, M. Abrasive water jet machining of titanium (Ti6Al4V)-CFRP stacks-A semianalytical modeling approach in the prediction of kerf geometry. J. Manuf. Process. 2019, 39, 327-337.

6. Kunčická, L.; Kocich, R.; Lowe, T.C. Advances in metals and alloys for joint replacement. Prog. Mater. Sci. 2017, 88, 232-280. [CrossRef] 
7. Nocivin, A.; Raducanu, D.; Vasile, B.; Trisca-Rusu, C.; Cojocaru, E.; Dan, A.; Irimescu, R.; Cojocaru, V. Tailoring a low young modulus for a beta titanium alloy by combining severe plastic deformation with solution treatment. Materials 2021, 14,3467 . [CrossRef]

8. Ozaltin, K.; Chrominski, W.; Kulczyk, M.; Panigrahi, A.; Horky, J.; Zehetbauer, M.; Lewandowska, M. Enhancement of mechanical properties of biocompatible Ti-45Nb alloy by hydrostatic extrusion. J. Mater. Sci. 2014, 49, 6930-6936. [CrossRef]

9. Wang, Z.; Chen, J.; Besnard, C.; Kunčická, L.; Kocich, R.; Korsunsky, A.M. In situ neutron diffraction investigation of texturedependent Shape Memory Effect in a near equiatomic NiTi alloy. Acta Mater. 2021, 202, 135-148. [CrossRef]

10. Greger, M.; Kocich, R.; Černý, M.; Kander, L. Properties of comercial pure titanium after equal channel angular pressing. In Proceedings of the Metal 2009 18th International Conference on Metallurgy and Materials, Hradec and Moravici, Czech Republic, 19-21 May 2009; Tanger Ltd: Ostrava, Czech Republic, 2009; pp. 516-520.

11. An, B.; Li, Z.; Diao, X.; Xin, H.; Zhang, Q.; Jia, X.; Wu, Y.; Li, K.; Guo, Y. In vitro and in vivo studies of ultrafine-grain Ti as dental implant material processed by ECAP. Mater. Sci. Eng. C 2016, 67, 34-41. [CrossRef]

12. Zhao, P.C.; Yuan, G.J.; Wang, R.Z.; Guan, B.; Jia, Y.F.; Zhang, X.C.; Tu, S.T. Grain-refining and strengthening mechanisms of bulk ultrafine grained CP-Ti processed by L-ECAP and MDF. J. Mater. Sci. Technol. 2021, 83, 196-207. [CrossRef]

13. Kocich, R.; Macháčková, A.; Andreyachshenko, V.A. A study of plastic deformation behaviour of Ti alloy during equal channel angular pressing with partial back pressure. Comput. Mater. Sci. 2015, 101, 233-241. [CrossRef]

14. Kunčická, L.; Kocich, R.; Drápala, J. Andreyachshenko, V. FEM simulations and comparison of the ecap and ECAP-PBP influence on Ti6Al4V alloy's deformation behaviour. In Proceedings of the Metal 2013 22nd International Conference on Metallurgy and Materials, Brno, Czech Republic, 15-17 May 2013; Tanger Ltd: Ostrava, Czech Republic, 2013; pp. 391-396.

15. Kocich, R.; Kursa, M.; Szurman, I.; Dlouhý, A. The influence of imposed strain on the development of microstructure and transformation characteristics of Ni-Ti shape memory alloys. J. Alloys Compd. 2011, 509, 2716-2722. [CrossRef]

16. Kocich, R.; Szurman, I.; Kursa, M.; Fiala, J. Fiala. Investigation of influence of preparation and heat treatment on deformation behaviour of the alloy NiTi after ECAE. Mater. Sci. Eng. A 2009, 512, 100-104. [CrossRef]

17. Sheremetyev, V.; Churakova, A.; Derkach, M.; Gunderov, D.; Raab, G.; Prokoshkin, S. Effect of ECAP and annealing on structure and mechanical properties of metastable beta Ti-18Zr-15Nb (at.\%) alloy. Mater. Lett. 2021, 305, 130760. [CrossRef]

18. Lin, Z.; Wang, L.; Xue, X.; Lu, W.; Qin, J.; Zhang, D. Microstructure evolution and mechanical properties of a Ti-35Nb-3Zr-2Ta biomedical alloy processed by equal channel angular pressing (ECAP). Mater. Sci. Eng. C 2013, 33, 4551-4561. [CrossRef] [PubMed]

19. Gupta, R.K.; Kumar, V.A.; Gururaja, U.V.; Subramani, K.; Prakash, U.; Chakravarthi, K.V.A.; Ramkumar, P.; Sarkar, P. Solution treatment and aging (STA) study of thick-wall ring from Titanium alloy Ti6Al4V. Met. Sci. Heat Treat. 2015, $717,47$.

20. Gupta, R.K.; Kumar, V.A.; Chhangani, S. Study on variants of solution treatment and aging cycle of titanium alloy Ti6Al4V. J. Mater. Eng. Perform. 2016, 25, 1492-1501. [CrossRef]

21. Ezugwu, E.O.; Wang, Z.M. Titanium alloys and their machinability-A review. J. Mater. Process. Technol. 1997, 68, 262-274. [CrossRef]

22. Yuan, Y.; Chen, J.; Gao, H.; Wang, X. An investigation into the abrasive waterjet milling circular pocket on titanium alloy. Int. J. Adv. Manuf. Technol. 2020, 107, 4503-4515. [CrossRef]

23. Hlaváč, L.M.; Gembalová, L.; Štěpán, P.; Hlaváčová, I.M. Improvement of abrasive water jet machining accuracy for titanium and TiNb alloy. Int. J. Adv. Manuf. Technol. 2015, 80, 1733-1740. [CrossRef]

24. Shipway, P.H.; Fowler, G.; Pashby, I.R. Characteristics of the surface of a titanium alloy following milling with abrasive waterjets. Wear 2005, 258, 123-132. [CrossRef]

25. Fowler, G.; Shipway, P.H.; Pashby, I.R. A technical note on grit embedment following abrasive water-jet milling of a titanium alloy. J. Mater. Process. Technol. 2005, 159, 356-368. [CrossRef]

26. Fowler, G.; Shipway, P.H.; Pashby, I.R. Abrasive water-jet controlled depth milling of Ti6Al4V alloy-An investigation of the role of jet-workpiece traverse speed and abrasive grit size on the characteristics of the milled material. J. Mater. Process. Technol. 2005, 161, 407-414. [CrossRef]

27. Fowler, G.; Pashby, I.R.; Shipway, P.H. The effect of particle hardness and shape when abrasive water jet milling of titanium alloy Ti6Al4V. Wear 2009, 266, 613-620. [CrossRef]

28. Arola, D.; McCain, M.L.; Kunaporn, S.; Ramulu, M. Waterjet and abrasive waterjet surface treatment of titanium: A comparison of surface texture and residual stress. Wear 2001, 249, 943-950. [CrossRef]

29. Arola, D.; Alade, A.E.; Weber, W. Improving fatigue strength of metals using abrasive waterjet peening. Mach. Sci. Technol. 2006, 10, 197-218. [CrossRef]

30. Hashish, M. A modeling study of metal-cutting with abrasive waterjets. J. Eng. Mater. Technol. 1984, 106, 88-100. [CrossRef]

31. Hashish, M. A model for abrasive-waterjet (AWJ) machining. J. Eng. Mater. Technol. 1989, 111, 154-162. [CrossRef]

32. Bitter, J.G.A. A study of erosion phenomena part 1. Wear 1963, 6, 5-21. [CrossRef]

33. Bitter, J.G.A. A study of erosion phenomena part 2. Wear 1963, 6, 169-190. [CrossRef]

34. Sheldon, G.L.; Finnie, I. On the ductile behavior of nominally brittle materials during erosive cutting. ASME J. Eng. Ind. 1966, 88, 387-392. [CrossRef]

35. Sheldon, G.L.; Finnie, I. The mechanism of material removal in the erosive cutting of brittle materials. ASME J. Eng. Ind. 1966, 88, 393-399. [CrossRef] 
36. Hlaváč, L.; Hlaváčová, I.; Gembalová, L.; Kaličinský, J.; Fabián, S.; Měšt'ánek, J.; Kmec, J.; Mádr, V. Experimental method for the investigation of the abrasive water jet cutting quality. J. Mater. Process. Technol. 2009, 209, 6190-6195. [CrossRef]

37. Singh, R.; Singh, V.; Gupta, T.V.K. An experimental study on surface roughness in slicing tungsten carbide with abrasive water jet machining. In Proceedings of the International Conference on Advances in Mechanical Engineering, ICAME 2020, Nagpur, India, 10-11 January 2020; Kalamkar, V.R., Monkova, K., Eds.; Springer: Singapore, 2021; pp. 353-359.

38. Hlaváč, L.M. Investigation of the abrasive water jet trajectory curvature inside the kerf. J. Mater. Process. Technol. 2009, 209, 4154-4161. [CrossRef]

39. Hlaváč, L. Revised model of abrasive water jet cutting for industrial use. Materials 2021, 10, 4032. [CrossRef]

40. Gupta, V.; Pandey, P.M.; Garg, M.P.; Khanna, R.; Batra, N.K. Minimization of kerf taper angle and kerf width using Taguchi's method in abrasive water jet machiningof marble. Procedia Mater. Sci. 2014, 6, 140-149. [CrossRef]

41. Shukla, R.; Singh, D. Experimentation investigation of abrasive water jet machining parameters using Taguchi and Evolutionary optimization techniques. Swarm Evol. Comput. 2017, 32, 167-183. [CrossRef]

42. Perec, A.; Pude, F.; Kaufeld, M.; Wegener, K. Obtaining the selected surface roughness by means of mathematical model based parameter optimization in abrasive waterjet cutting. Stroj. Vestn. J. Mech. Eng. 2017, 63, 606-613. [CrossRef]

43. Masoud, F.; Sapuan, S.M.; Ariffin, M.K.A.M.; Nukman, Y.; Bayraktar, E. Experimental analysis of kerf taper angle in cutting process of sugar palm fiber reinforced unsaturated polyester composites with laser beam and abrasive water jet cutting technologies. Polymers 2021, 13, 2543. [CrossRef] [PubMed]

44. Hlaváč, L.M.; Krajcarz, D.; Hlaváčová, I.M.; Spadło, S. Precision comparison of analytical and statistical-regression models for AWJ cutting. Precis. Eng. J. Int. Soc. Precis. Eng. Nanotechnol. 2017, 50, 148-159. [CrossRef]

45. Zeng, J.Y.; Kim, T.J. An erosion model of polycrystalline ceramics in abrasive waterjet cutting. Wear 1996, 193, 207-217. [CrossRef]

46. Momber, A.W. Stress-strain relation for water-driven particle erosion of quasi-brittle materials. Theor. Appl. Fract. Mec. 2001, 35, 19-37. [CrossRef]

47. Paul, S.; Hoogstrate, A.M.; Luttervelt, C.A.; Kals, H.J.J. Analytical modelling of the total depth of cut in the abrasive water jet machining of polycrystalline brittle material. J. Mater. Process. Technol. 1998, 73, 206-212. [CrossRef]

48. Srinivas, S.; Babu, N.R. An analytical model for predicting depth of cut in abrasive waterjet cutting of ductile materials considering the deflection of jet in lateral direction. Int. J. Abras. Technol. 2009, 2, 259-278. [CrossRef]

49. Paul, S.; Hoogstrate, A.M.; Luttervelt, C.A.; Kals, H.J.J. Analytical and experimental modelling of the abrasive water jet cutting of ductile materials. J. Mater. Process. Technol. 1998, 73, 189-199. [CrossRef]

50. Deam, R.T.; Lemma, E.; Ahmed, D.H. Modelling of the abrasive water jet cutting process. Wear 2004, 257, 877-891. [CrossRef]

51. CorelDRAW ${ }^{\circledR}$ Home E Student 2018; Graphics Suite; Corel Corporation: Ottawa, ON, Canada, 2018.

52. Kunčická, L.; Kocich, R. Deformation behaviour of $\mathrm{Cu}-\mathrm{Al}$ clad composites produced by rotary swaging. In Proceedings of the 5th Global Conference on Polymer and Composite Materials (PCM 2018), Kitakyushu, Japan, 10-13 April 2018; p. 012029. [CrossRef]

53. Kunčická, L.; Kocich, R.; Dvořák, K.; Macháčková, A. Rotary swaged laminated Cu-Al composites: Effect of structure on residual stress and mechanical and electric properties. Mater. Sci. Eng. A 2019, 742, 743-750. [CrossRef] 